\title{
Changes in serum lactate dehydrogenase levels as markers of pathological response and prognosis in colorectal liver metastases patients receiving neoadjuvant chemotherapy followed by resection
}

\author{
Jinghua Chen ${ }^{1 \#}$, Qichen Chen ${ }^{1 \#}$, Jinjie Yao ${ }^{1}$, Yujuan Jiang ${ }^{2}$, Jianguo Zhou ${ }^{1}$, Hong Zhao ${ }^{1}$, Jianqiang Cai ${ }^{1}$ \\ ${ }^{1}$ Department of Hepatobiliary Surgery, National Cancer Center/National Clinical Research Center for Cancer/Cancer Hospital, Chinese Academy \\ of Medical Sciences and Peking Union Medical College, Beijing, China; ${ }^{2}$ Department of Colorectal Surgery, National Cancer Center/National \\ Clinical Research Center for Cancer/Cancer Hospital, Chinese Academy of Medical Sciences and Peking Union Medical College, Beijing, China \\ Contributions: (I) Conception and design: J Chen, Q Chen; (II) Administrative support: J Yao; (III) Provision of study materials or patients: Q Chen, \\ H Zhao, J Zhou; (IV) Collection and assembly of data: J Chen, Y Jiang; (V) Data analysis and interpretation: Chen, Q Chen; (VI) Manuscript writing: \\ All authors; (VII) Final approval of manuscript: All authors. \\ \#These authors contributed equally to this work. \\ Correspondence to: Jianguo Zhou; Hong Zhao. No. 17, Panjiayuan South Lane, Chaoyang District, Beijing, China. Email: zjg13311533776@126.com; \\ pumczhaohong@126.com.
}

Background: This study sought to evaluate the effects of pre-neoadjuvant chemotherapy lactate
dehydrogenase (pre-NAC LDH) levels, preoperative LDH levels, and changes in LDH levels on the
pathological response and outcomes of colorectal liver metastases (CRLM) patients treated with liver
resection after NAC.

Methods: This study included 152 colorectal CRLM patients, who underwent NAC followed by liver resection. Patients were excluded if they were diagnosed with other malignancies or lacked follow-up and clinical data. Demographic and clinicopathological data were collected from hospital records. Pathological response and postoperative complications were measured according to the tumor regression grade (TRG) and Clavien-Dindo classification system, respectively. The optimal cutoff values were determined by the receiver operating characteristic curve and the X-tile analysis. Changes in LDH levels were graded as 0, 1, and 2. A logistic regression analysis was conducted to identify the independent predictors of pathological response and postoperative major complications. Univariate and multivariate Cox regression analyses were used to identify the independent risk factors of progression-free survival (PFS) and overall survival (OS).

Results: The multivariate analysis indicated that a grade $2 \mathrm{LDH}$ level change was a risk factor of an unfavorable histological response [odds ratio (OR) 0.249, 95\% confidence interval (CI): 0.066-0.942; $\mathrm{P}=0.041]$ and major postoperative complications (OR 2.523, 95\% CI: 1.179-10.530; $\mathrm{P}=0.024$ ), which were independent of other clinical covariates. A pre-NAC LDH level $\geq 145$ IU/L [hazards ratio (HR) 0.584 , 95\% CI: 0.359-0.950; P=0.030], a grade 1 LDH level change (HR 0.584, 95\% CI: 0.359-0.950; P=0.030) and a grade $2 \mathrm{LDH}$ level change (HR 0.447, 95\% CI: 0.231-0.864; $\mathrm{P}=0.017$ ) were independent prognostic predictors of PFS. A preoperative a LDH level $\geq 231$ IU/L (HR 0.405, 95\% CI: $0.192-0.852 ; \mathrm{P}=0.017$ ) and a grade 2 LDH level change (HR 0.362, 95\% CI: 0.157-0.834; P=0.017) were independent prognostic factors of OS, which were independent of other clinical covariates.

Conclusions: LDH levels and changes in LDH levels are potentially useful biomarkers for predicting the pathological response and prognosis of CRLM patients receiving NAC followed by liver resection.

Keywords: Colorectal liver metastases (CRLM); lactate dehydrogenase (LDH); pathological response; prognosis 
Submitted Mar 14, 2021. Accepted for publication Aug 04, 2021.

doi: 10.21037/apm-21-584

View this article at: https://dx.doi.org/10.21037/apm-21-584

\section{Introduction}

Colorectal cancer (CRC) is the fourth most deadly cancer causing almost 900,000 deaths annually worldwide (1) and at least $50 \%$ of CRC patients develop liver metastases $(2,3)$. However, only $15-25 \%$ of CRC patients can undergo liver resection as a potentially curative treatment (4). The clinical outcome for patients with colorectal liver metastases (CRLM) has been improved greatly due to surgical resection, leading to 5-year overall survival (OS) rates ranging $31-60 \%$. Nevertheless, the high recurrence rate of $50-75 \%$ after liver resection remains a major problem $(5,6)$. For CRLM patients with high-risk recurrence factors, the administration of neoadjuvant chemotherapy (NAC) can improve their survival by down-staging the disease, treating micro-metastases, and increasing the complete resection rate. As an important indicator for chemotherapy efficacy, the favorable pathological response rate to NAC was only approximately $50 \%$ (7-9). Thus, to guide the therapy management of CRLM patients, it is crucial to explore and identify predictors related to the efficacy of NAC and prognosis.

Previous studies have shown that various factors are independent prognostic factors in patients with CRLM. Kim et al. (10) found that primary tumor location had a prognostic effect in patients who underwent simultaneous liver resection for CRLM, and right-sided tumors with the KRAS-mutation yielded the worst oncological outcome. Chen et al. (11) showed that preoperative D-dimer and GGT levels were reliable biomarkers in predicting major postoperative complications or survival of CRLM patients after hepatic resection. Further, Frühling et al. (12) found that a high preoperative Glasgow Prognostic Score, measured by preoperative C-reactive protein and albumin, was correlated with poor survival in CRLM patients.

Serum lactate dehydrogenase (LDH) levels are related to tumor prognosis, and changes in $\mathrm{LDH}$ can be used to monitor the chemotherapeutic effects of extensive cancer. Notably, LDH assays are relatively inexpensive and easy to perform. Thus, we focused on the prognostic value of serum LDH levels. As a key enzyme of glycolysis with a wide distribution in tissues, $\mathrm{LDH}$ catalyzes the reversible transformation of pyruvate to lactate under anaerobic conditions (13). Glycolysis is elevated in most malignant cells and provides the largest proportion of energy needed for cell proliferation. $\mathrm{LDH}$ is overexpressed in hypoxic cancer cells, and research has shown a correlation between hypoxia and systemic inflammation, which is the seventh hallmark of cancer $(14,15)$. Serum LDH levels serve as a prognostic marker of various malignancies, including lung cancer (16), CRC (17), gastric cancer (18), breast cancer (19). Changes in LDH levels have been associated with a risk of treatment failure in patients with mature B-cell nonHodgkine's lymphoma. However, only limited data are available on the effects of LDH and changes in LDH levels on the pathological response and outcomes of CRLM patients. Therefore, we focused on the prognostic value of changes in serum LDH levels in patients with CRLM.

To our knowledge, this study is the first to investigate the predictive role of serum LDH levels in patients with CRLM treated by liver resection followed by NAC. This study aimed to evaluate the effects of preoperative $\mathrm{LDH}$ serum levels, pre-NAC LDH serum levels, and variations in LDH serum levels on pathological response and prognosis of patients. We present the following article in accordance with the REMARK reporting checklist (available at https:// dx.doi.org/10.21037/apm-21-584).

\section{Methods}

\section{Patients and treatments}

We reviewed the data of CRLM patients at the Cancer Hospital Chinese Academy of Medical Sciences from January 2010 to December 2018. To be eligible to participate in this study, patients had to meet the following inclusion criteria: (I) pathologically diagnosed with colorectal adenocarcinoma liver metastases; and (II) received NAC followed by liver resection. Patients were excluded from the study if they were diagnosed with other malignancies or lacked followup and clinical data. Ultimately, 152 patients met the above criteria at our hospital and were included in this study. The flow diagram depicting the process used to select the CRLM patients was shown in Figure 1. The study was conducted in accordance with the Declaration of Helsinki (as revised in 2013). The study was approved by the Institutional Review 


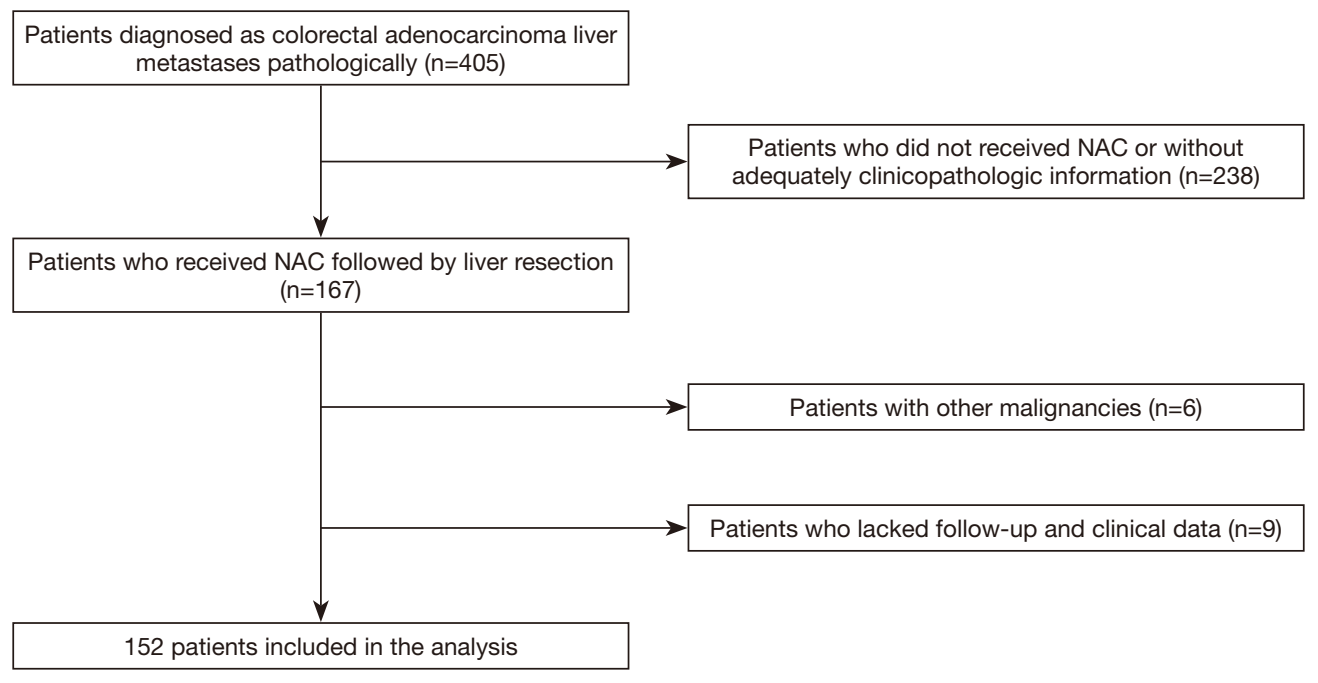

Figure 1 Flow diagram for the selection of CRLM patients. NAC, neoadjuvant chemotherapy; CRLM, colorectal liver metastases.

Board of the Ethics Committee of Cancer Hospital Chinese Academy of Medical Sciences (ID NCC2019C-016). All included patients gave their informed consent to participate in the study.

Demographic and clinicopathological data were collected from hospital records, including age, sex, body mass index (BMI), comorbidity, and American Society of Anesthesiology (ASA) score. Liver resection was defined as major or minor liver resection. NAC were administered to patients with high clinical risk-scoring system scores or initially unresectable liver metastases. The NAC regimens consisted of 5 -fluorouracil/capecitabine and oxaliplatin or irinotecan with or without targeted agents, such as bevacizumab or cetuximab. Within 4-6 weeks of the completion of NAC, patients underwent liver resection. Computed tomography (CT) or magnetic resonance imaging (MRI) scans were used to evaluate NAC clinical responses of patients according to the Response Evaluation Criteria in Solid Tumors (RECIST1.1) (20). Tumor regression grade (TRG) was used to measure the pathological response (21); a pathological TRG of 1-3 represented a favorable response to NAC. We used peripheral venepuncture to collect blood samples to evaluate the serum LDH levels of patients (normal range: 120-250 U/L) 1 week before NAC and 1 week before surgery. All information was summarized in Table 1.

\section{Follow-up and endpoints}

Patients in the study were followed-up with regularly.
Specifically, patients were followed-up with 1 month after surgery, and every 3 months thereafter. CT/MRI scans and serum carcinoembryonic antigen (CEA) measurements were routinely conducted. Progression-free survival (PFS) and OS were the primary outcomes. PFS was defined as the interval from the date of diagnosis to the date of progression or the last follow-up date. OS was defined as the interval from the date of diagnosis to the date of death or the last follow-up date. The subordinate outcome was postoperative complications, the severity of which was described according to the Clavien-Dindo classification system (22). Clavien-Dindo scores of III-V were classified as major complications.

\section{Statistical analysis}

The optimal cutoff values of pre-NAC LDH levels and preoperative LDH levels for histological response and postoperative complications were identified by the highest Youden index (sensitivity + specificity -1$)$. X-tile analysis was performed to investigate the optimal cutoff values of LDH for OS as the optimal cutoff values of survival. We divided the LDH levels into two groups according to the cutoff values and compared the demographic and clinicopathological data of different groups. Based on the changes in pre-NAC LDH level and preoperative LDH level, we established the LDH change scores as follows: 0 (both pre-NAC and preoperative LDH level < cut-off value), 2 (both pre-NAC and preoperative LDH level $\geq$ cut-off value), and 1 (other combinations). Categorical 


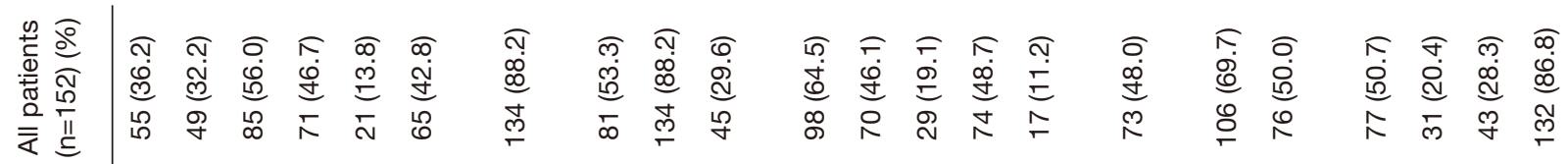

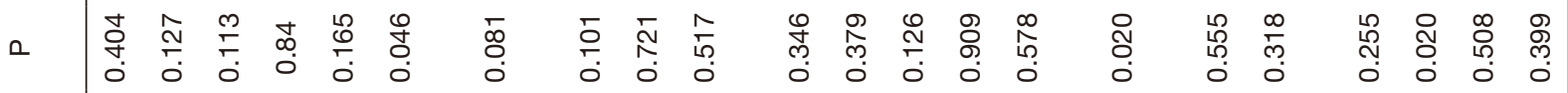

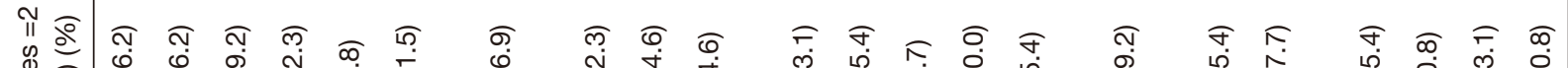

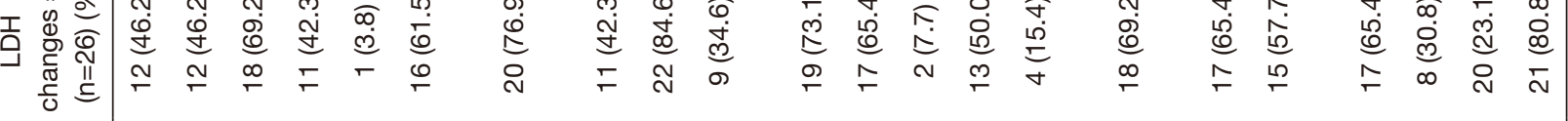

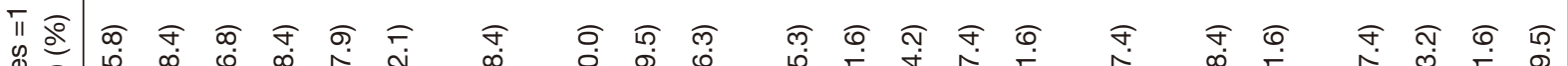

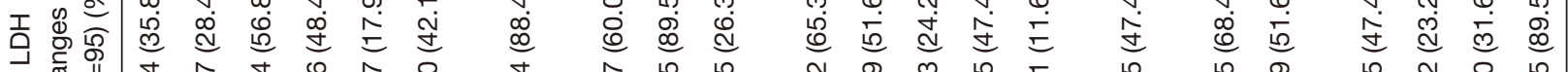

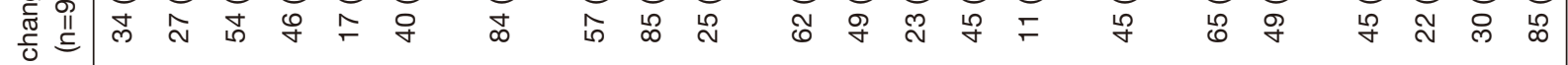

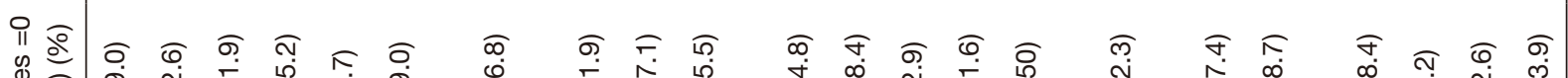

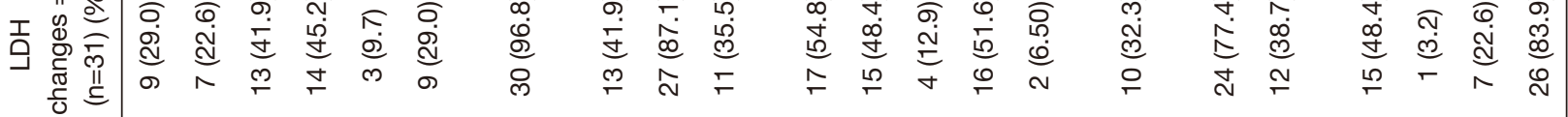

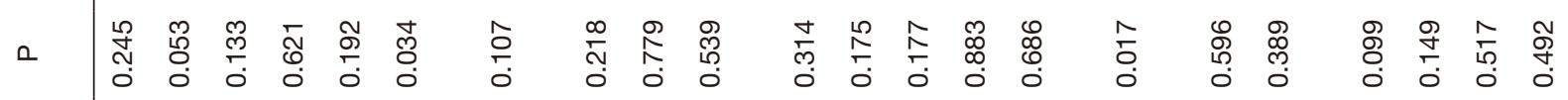

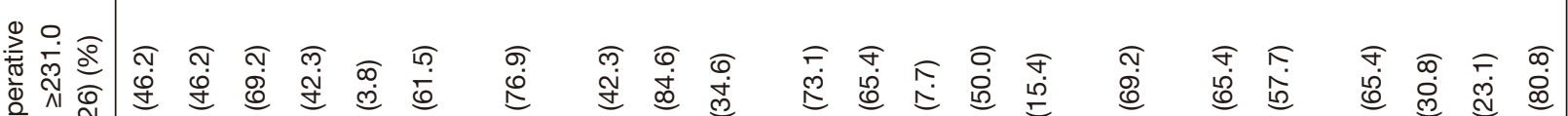

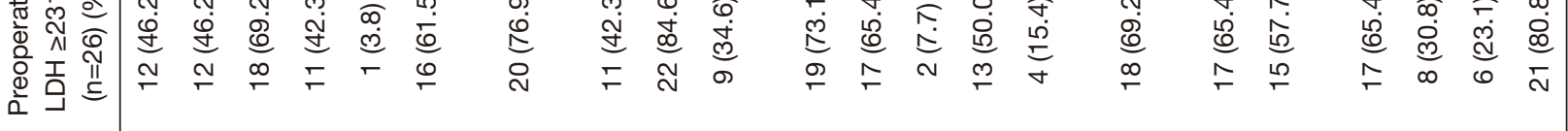

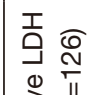

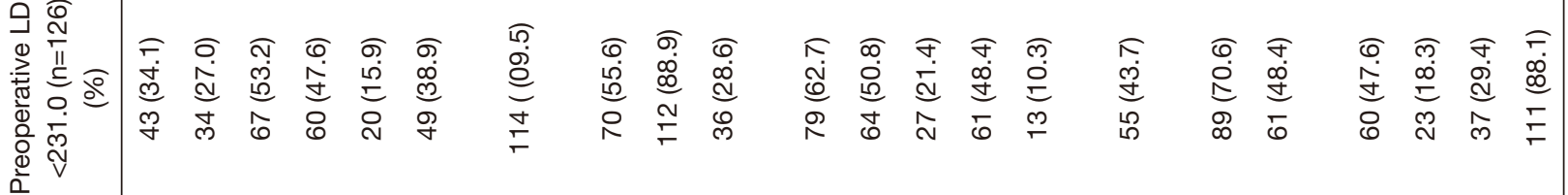

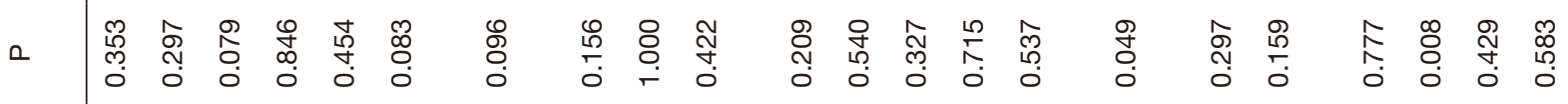

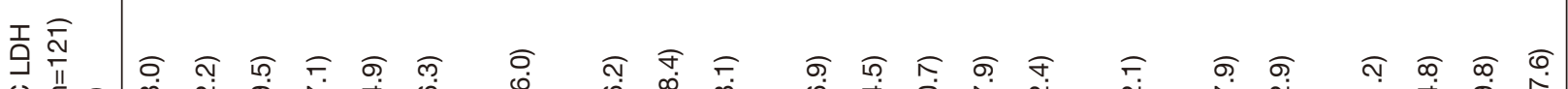

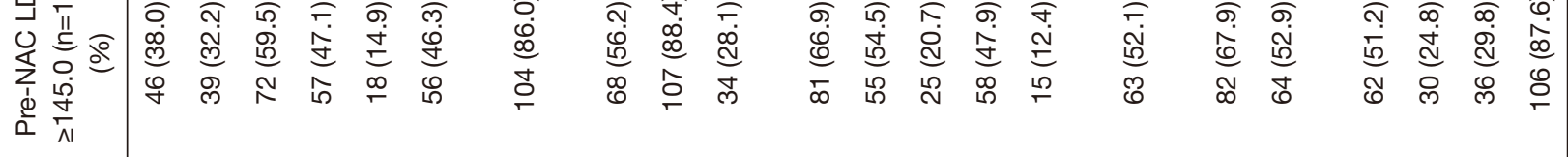

I $\widehat{\bar{m}}$

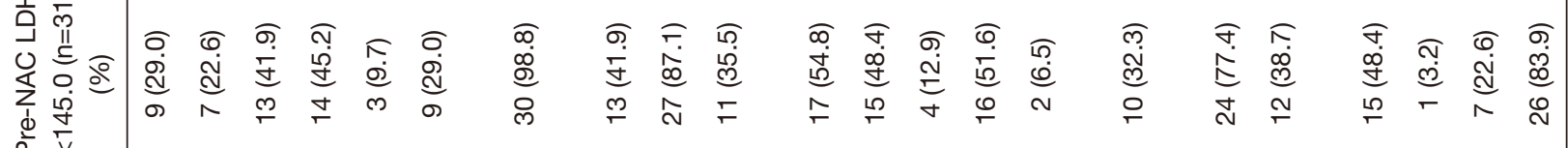




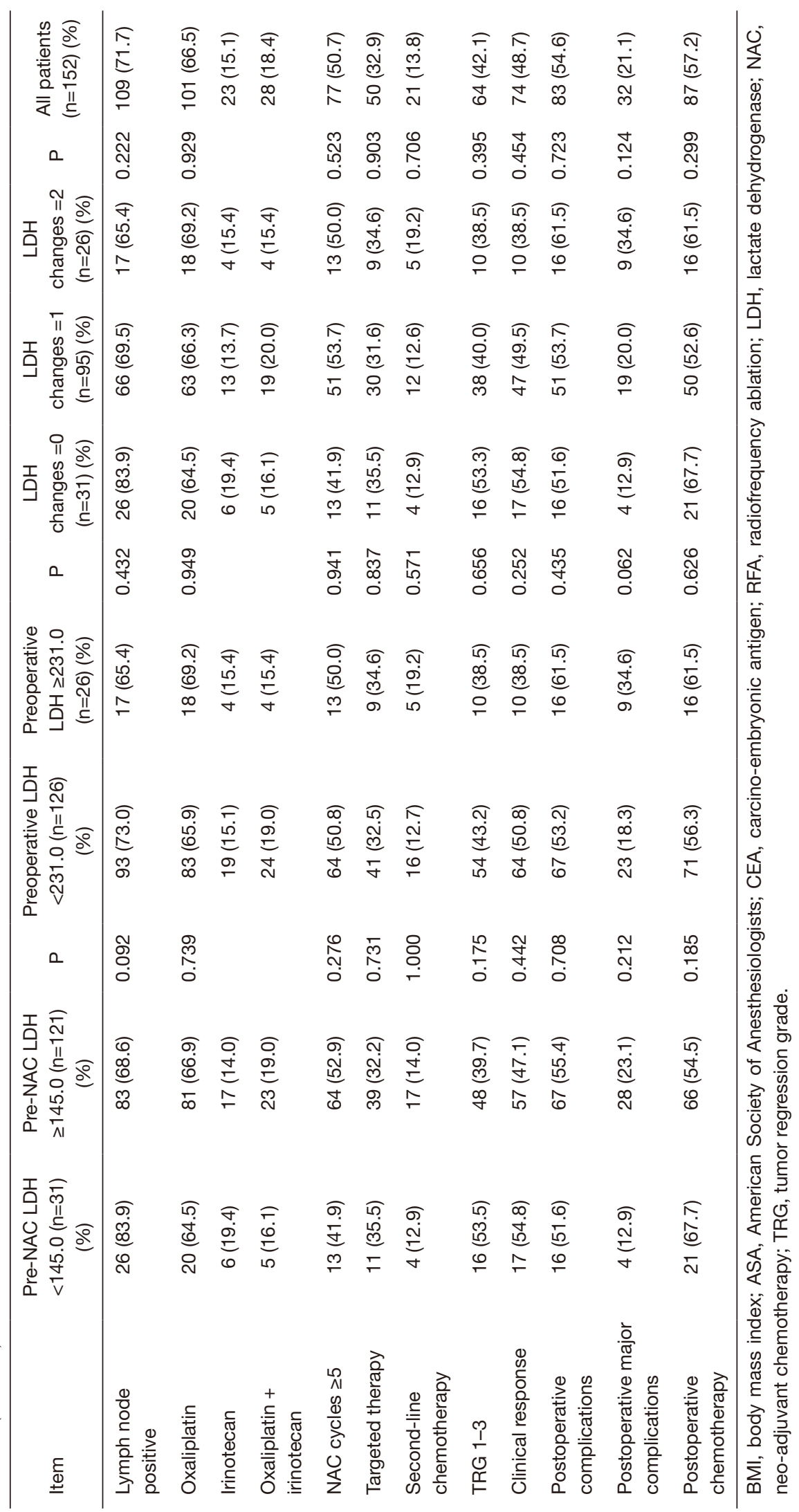


variables were analyzed by Chi-square or Fisher's exact test and continuous variables were analyzed by the MannWhitney U test. Survival was calculated using the KaplanMeier method and compared by the log-rank test. The relationships between tumor characteristics and pathological response, postoperative major complications were detected by the multivariable logistic regression analysis. Univariate and multivariate Cox regression models were performed for the analyses of survival. Factors with $\mathrm{P}<0.10$ by univariate analysis were retained in multivariate models. A twotailed $\mathrm{P}$ value of less than 0.05 was considered significant. All analyses were performed using the SPSS 23.0 and GraphPad Prism 8.0.

\section{Results}

\section{Clinicopathological characteristics}

Of the 152 patients, 103 were male $(67.8 \%)$ and 49 were female $(32.2 \%)$. Patients had a median age of 56 years [interquartile range (IQR): 50-63 years]. Eighty-five patients $(56.0 \%)$ had a $\mathrm{BMI} \geq 24 \mathrm{~kg} / \mathrm{m}^{2}$. Comorbidities were discovered in $46.7 \%$ of patients (71/152). Only $13.8 \%$ of patients (21/152) had an ASA score of 3-4. A total of $42.8 \%$ of patients $(65 / 152)$ had a CEA of $\geq 10 \mathrm{ng} / \mathrm{mL}$. The primary tumor site in approximately half of the patients $(53.5 \%, 81 / 152)$ was the colon. Poorly differentiated and T3-T4 primary tumor stages were observed in $28.3 \%$ (43/152) and $86.8 \%(132 / 152)$ of patients, respectively. The majority of patients $(88.2 \%, 134 / 152)$ had synchronous liver metastases. The bilobar liver metastases distribution was observed in 74 patients (48.7\%). One hundred and six patients $(69.7 \%)$ had multiple liver metastasis. Patients had a median of three liver metastases (IQR: 1.0-4.0) and the median liver metastasis diameter was $2.8 \mathrm{~cm}$ (IQR: 1.8$4.0 \mathrm{~cm}$ ). Positive lymph nodes were detected in 109 patients $(71.7 \%)$. Heterochronous resection and major liver resection were performed in $29.6 \%(45 / 152)$ and $46.1 \%$ (70/152) of patients, respectively. The median operation time was 337.5 (IQR: 256.3-408.0) $\mathrm{min}$ and the median blood loss was $300.0 \mathrm{~mL}$ (IQR: $150.0-400.0 \mathrm{~mL}$ ). The percentage of intraoperative blood transfusion was $20.4 \%$ during surgery. One hundred and twenty-nine patients $(84.9 \%)$ received an oxaliplatin-based regimen. Fifty patients $(32.9 \%)$ and $21(13.8 \%)$ patients received targeted therapy and second-line therapy, respectively. The median number of NAC cycles was 5 and 77 patients $(50.7 \%)$ received no less than 5 NAC cycles. Eighty- seven patients $(57.2 \%)$ underwent adjuvant chemotherapy after surgery. A poor clinical and pathological response was observed in $48.7 \%(74 / 152)$ and $42.1 \%$ (64/152) of patients, respectively (see Table 1).

\section{Analyses of the optimal cutoff point for $\mathrm{LDH}$}

The mean pre-NAC and preoperative LDH levels of patients were $235.1 \pm 216.1$ and $197.3 \pm 78.3 \mathrm{IU} / \mathrm{L}$, respectively $(\mathrm{P}<0.001)$. The optimal cutoff values of pre-NAC LDH and pre-NAC LDH levels for major postoperative complications were 142.5 and $186.5 \mathrm{IU} / \mathrm{L}$, respectively. A pre-NAC LDH level $\geq 142.5$ IU/L and preoperative LDH level of $\geq 186.5$ IU/L were observed in 130 patients $(85.5 \%)$ and 71 patients (46.7\%), respectively. The optimal cutoff of pre-NAC LDH and pre-NAC LDH levels for the histological response was 200.0 and 217.0 IU/L, respectively. A pre-NAC LDH level $\geq 200.0$ IU/L was found in 58 patients $(38.2 \%$ ), and a preoperative $\mathrm{LDH}$ level of $\geq 217.0 \mathrm{IU} / \mathrm{L}$ was found in 37 patients (24.3\%). Additionally, the optimal cutoff values of pre-NAC LDH and pre-NAC LDH levels for survival were 145.0 and $231.0 \mathrm{IU} / \mathrm{L}$, respectively. A preNAC LDH level $\geq 145.0$ and a preoperative LDH level of $\geq 231.0 \mathrm{IU} / \mathrm{L}$ were observed in 121 patients $(79.6 \%)$ and 26 patients $(17.1 \%)$, respectively.

\section{Effect of serum LDH levels on histological response}

The univariate analysis showed that a pre-NAC LDH level $\geq 142.5 \mathrm{IU} / \mathrm{L}(\mathrm{P}=0.083)$ and a preoperative $\mathrm{LDH}$ level $\geq 186.5 \mathrm{IU} / \mathrm{L}(\mathrm{P}=0.093)$ were not significantly related to pathological response. A BMI $\geq 24 \mathrm{~kg} / \mathrm{m}^{2}$ $(\mathrm{P}=0.045)$, a primary tumor site in the right hemicolon $(\mathrm{P}=0.006)$, poor differentiation $(\mathrm{P}=0.023)$, targeted therapy $(\mathrm{P}<0.001)$, clinical response $(\mathrm{P}=0.003)$, and $\mathrm{LDH}$ level change $(\mathrm{P}=0.026)$ were significantly associated with poor pathological response. The multivariate analysis indicated that a grade $2 \mathrm{LDH}$ level change (OR 0.249, 95\% CI: 0.066-0.942; $\mathrm{P}=0.041$ ) independently predicted histological response. Additionally, a primary tumor site in the right hemicolon (OR 3.761, 95\% CI: 1.060-13.344; $\mathrm{P}=0.040$ ), multiple metastases (OR 0.365, 95\% CI: 0.151-0.884; $\mathrm{P}=0.026$ ), poor differentiation (OR 0.355, 95\% CI: $0.137-$ 0.916; $\mathrm{P}=0.032$ ), targeted therapy (OR 5.570, 95\% CI: 2.347-13.219; $\mathrm{P}<0.001)$ and clinical response (OR 2.337, 95\% CI: $1.058-5.165 ; \mathrm{P}=0.036)$ were independent risk factors of the histological response (see Table 2). 
Table 2 Prognostic factors for the pathological response in patients who underwent neo-adjuvant chemotherapy

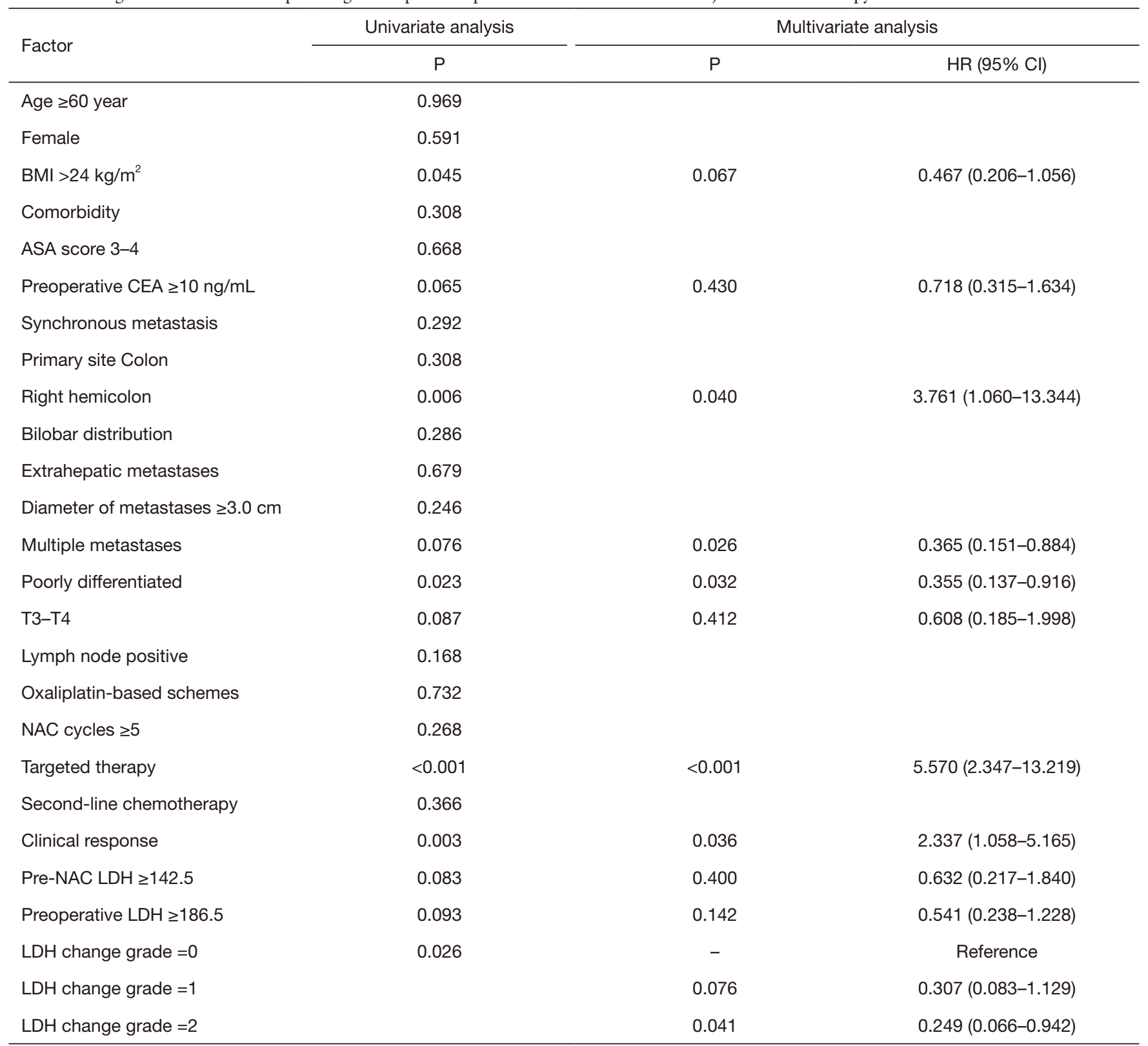

BMI, body mass index; ASA, American Society of Anesthesiologists; CEA, carcino-embryonic antigen; NAC, neo-adjuvant chemotherapy; $\mathrm{LDH}$, lactate dehydrogenase.

\section{Effect of serum LDH levels on major postoperative complications}

In this study, 83 patients $(54.6 \%)$ had postoperative complications, of which 32 were major, and 51 were minor. Thirty patients suffered from surgery-related complications, 37 suffered general complications, and 16 suffered from both surgery-related complications and general complications. The univariate analysis revealed that a preoperative $\mathrm{LDH}$ level $\geq 217 \mathrm{IU} / \mathrm{L}(\mathrm{P}=0.004)$, LDH level change $(\mathrm{P}=0.016)$, and second-line chemotherapy $(\mathrm{P}=0.019)$ were significantly associated with poor pathological response. The multivariate analysis indicated that a grade 2 LDH level change (OR 3.523, 95\% CI: 1.179-10.530; $\mathrm{P}=0.024)$ and second-line chemotherapy (OR 3.562, 95\% 
CI: $1.214-10.949 ; \mathrm{P}=0.021)$ were significantly associated with postoperative major complications (see Table 3).

\section{Effect of pre-NAC LDH level and preoperative LDH level on survival}

By the end of the follow-up period, $58.6 \%$ of patients had died, and $82.2 \%$ had relapsed. The median OS was 42.5 months (95\% CI: 32.0-53.0), and the median PFS was 7.9 months (95\% CI: 5.6-10.2). The 1 - and 3 -year PFS rates were $32.2 \%$ and $18.4 \%$, respectively. The $1-$, 3 - and 5 -year OS rates were $91.4 \%, 51.1 \%$ and $30.9 \%$, respectively.

Elevated pre-NAC LDH levels were significantly correlated with better PFS (mPFS: 8.1 months vs. 5.1 months; $\mathrm{P}=0.016$; see Figure $2 A$ ); however, elevated preoperative $\mathrm{LDH}$ levels were not correlated with PFS (mPFS: $8.1 \mathrm{vs.}$ 7.1 months; $\mathrm{P}=0.062$; see Figure $2 B$ ). Elevated pre-NAC LDH levels had no significant effect on OS (mOS:36.8 vs. 35.2 months; $\mathrm{P}=0.306$; see Figure $2 C$ ), and elevated preoperative $\mathrm{LDH}$ levels had no significant effect on OS (mOS: 57.7 vs. 35.2 months; $\mathrm{P}=0.079$; see Figure 2D). LDH level changes were significantly correlated with better PFS (mPFS: 5.1 vs. 8.0 months vs. 8.1 months; $\mathrm{P}=0.020$; see Figure 3A); however, LDH level changes were not correlated with OS (mOS: 35.2 vs. 34.6 vs. 57.6 months; $\mathrm{P}=0.177$; see Figure 3B).

The univariate analysis revealed that a pre-NAC $\geq 145$ IU/L (HR 0.601, 95\% CI: 0.395-0.914; $\mathrm{P}=0.017$ ), a grade $1 \mathrm{LDH}$ level change (HR 0.649, 95\% CI: $0.423-$ 0.997; $\mathrm{P}=0.048$ ), and a grade $2 \mathrm{LDH}$ level change (HR 0.440, 95\% CI: $0.240-0.806$; $\mathrm{P}=0.008$ ) were significantly associated with PFS. The univariate analysis also revealed R0 resection (HR 0.476, 95\% CI: 0.331-0.687; P $<0.001$ ), major resection (HR 1.485, 95\% CI: 1.041-2.118; $\mathrm{P}=0.029)$, radiofrequency ablation (RFA) (HR 1.760, 95\% CI: 1.105-2.695; $\mathrm{P}=0.009$ ), bilobar distribution (HR 1.739, 95\% CI: 1.220-2.479; $\mathrm{P}=0.002$ ), multiple metastases (HR 2.134, 95\% CI: $1.415-3.219, \mathrm{P}<0.001)$, lymph node positive (HR 1.795, 95\% CI: 1.177-2.738; $\mathrm{P}=0.007$ ), NAC cycles $\geq 5$ (HR 1.454, 95\% CI: 1.022-2.070; $\mathrm{P}=0.038$ ), second-line chemotherapy (HR 1.820, 95\% CI: 1.113-2.977; $\mathrm{P}=0.017$ ), TRG (HR 0.611, 95\% CI: 0.424-0.881; $\mathrm{P}=0.008$ ), and postoperative chemotherapy (HR 0.693, 95\% CI: $0.487-$ 0.988; $\mathrm{P}=0.042$ ) had significantly predictive effects for PFS. The multivariate analysis indicated that a pre-NAC $\geq 145$ IU/L (HR 0.584, 95\% CI: 0.359-0.950; $\mathrm{P}=0.030$ ), a grade $1 \mathrm{LDH}$ level change (HR $0.584,95 \% \mathrm{CI}$ :
0.359-0.950; $\mathrm{P}=0.030$ ), and a grade $2 \mathrm{LDH}$ level change (HR 0.447, 95\% CI: 0.231-0.864; $\mathrm{P}=0.017$ ) significantly predicted PFS and R0 resection (HR 0.629, 95\% CI: 0.415 0.954; $\mathrm{P}=0.029$ ), TRG (HR 0.535, 95\% CI: 0.352-0.814; $\mathrm{P}=0.003$ ) and postoperative chemotherapy (HR 0.690, 95\% CI: $0.476-1.000 ; \mathrm{P}=0.050$ ) as independent predictors of PFS (see Table 4).

The univariate analysis indicated that the following factors had possible predictive effects for OS: R0 resection (HR 0.039, 95\% CI: 0.256-0.596; $\mathrm{P}<0.001$ ), bilobar distribution (HR 1.172, 95\% CI: 1.125-2.605; $\mathrm{P}=0.012$ ), multiple metastases (HR 1.719, 95\% CI: 1.060-2.786; $\mathrm{P}=0.028$ ), positive lymph nodes (HR 1.776, 95\% CI: 1.058 2.981; $\mathrm{P}=0.030$ ), second-line chemotherapy (HR 2.137, 95\% CI: $1.220-3.745 ; \mathrm{P}=0.008$ ), TRG (HR 0.618, 95\% CI: 0.400-0.955, $\mathrm{P}=0.030$ ), postoperative complications (HR $2.369,95 \%$ CI: $1.536-3.653 ; \mathrm{P}<0.001)$, and postoperative chemotherapy (HR 0.544, 95\% CI: 0.358-0.826; $\mathrm{P}=0.004$ ). A preoperative $\mathrm{LDH} \geq 231$ and a grade $2 \mathrm{LDH}$ level change tended to indicate better $\mathrm{OS}(\mathrm{P}<0.1)$. The multivariate analysis indicated that a preoperative $\mathrm{LDH} \geq 231 \mathrm{IU} / \mathrm{L}$ (HR 0.405, 95\% CI: 0.192-0.852; $\mathrm{P}=0.017)$ and a grade $2 \mathrm{LDH}$ level change (HR 0.362, 95\% CI: 0.157-0.834; $\mathrm{P}=0.017$ ) were independent predictors of OS. The multivariate analysis also found that R0 resection (HR 0.378, 95\% CI: 0.231-0.619; $\mathrm{P}<0.001$ ), second-line chemotherapy (HR 3.091, 95\% CI: $1.578-6.054 ; \mathrm{P}=0.001$ ), postoperative complications (HR 2.566, 95\% CI: 1.596-4.216, P<0.001), and postoperative chemotherapy (HR $0.453,95 \%$ CI: $0.285-0.721 ; \mathrm{P}=0.001$ ) could predicted OS independently (see Table 5).

\section{Discussion}

This study was the first to investigate the predictive value of changes in serum LDH levels on pathological response, major postoperative complications, and OS in CRLM patients treated by surgery followed NAC. A grade $2 \mathrm{LDH}$ level change was significantly associated with a poor pathological response and the occurrence of major postoperative complications. Further, a preoperative $\mathrm{LDH} \geq 231 \mathrm{IU} / \mathrm{L}$ and a pre-NAC LDH $\geq 145 \mathrm{IU} / \mathrm{L}$ were identified as independent predictive factors of OS and PFS, respectively. Additionally, patients with a grade $2 \mathrm{LDH}$ level change had significantly better survival outcomes compared with other grades.

Serum LDH level is an indirect marker of tumor hypoxia, neo-angiogenesis, metastasis, and development in 
Table 3 Prognostic factors for postoperative major complications in colorectal liver metastases patients after surgery

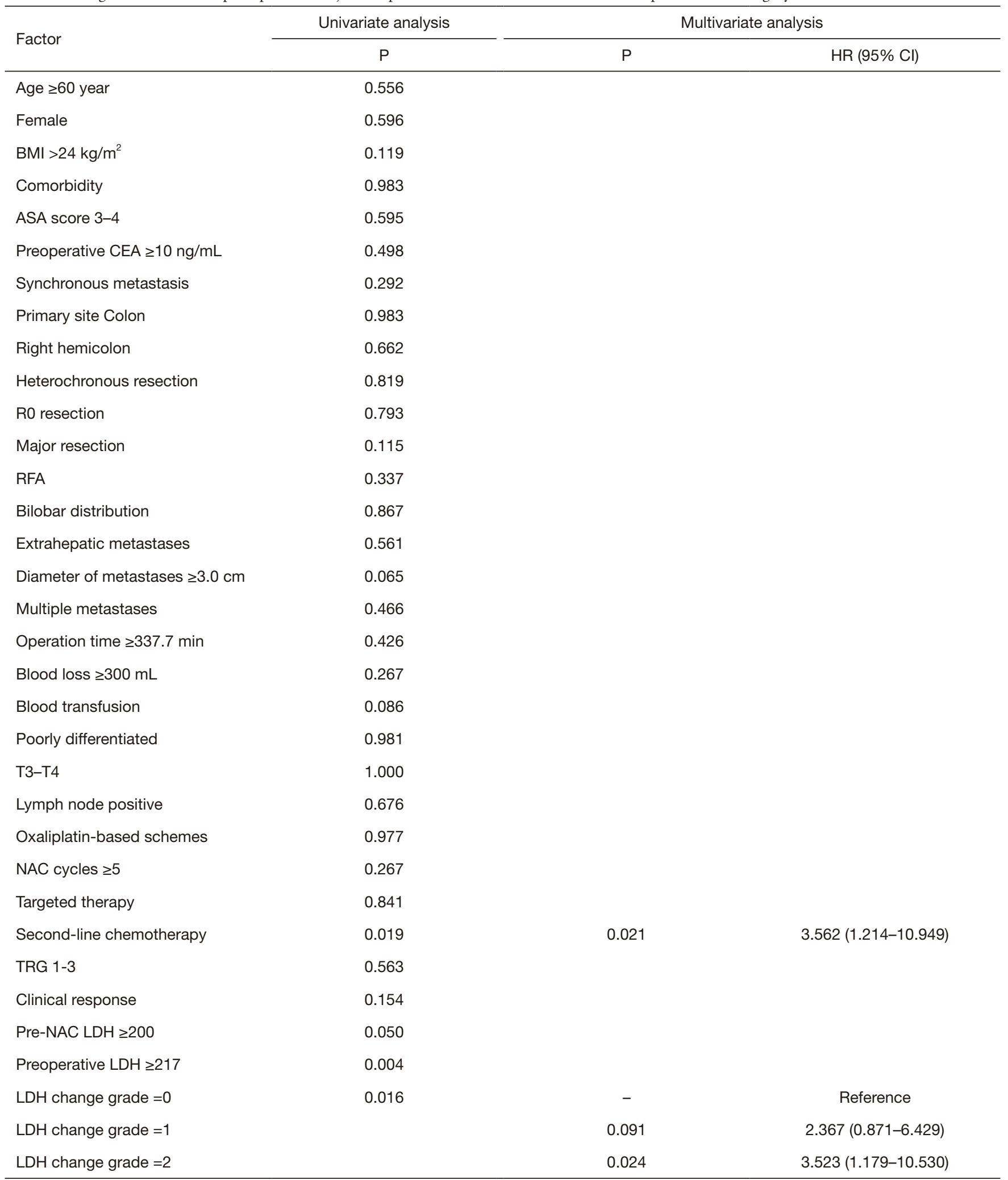

BMI, body mass index; ASA, American Society of Anesthesiologists; CEA, carcino-embryonic antigen; RFA, radiofrequency ablation; LDH, lactate dehydrogenase; NAC, neo-adjuvant chemotherapy; TRG, tumor regression grade. 

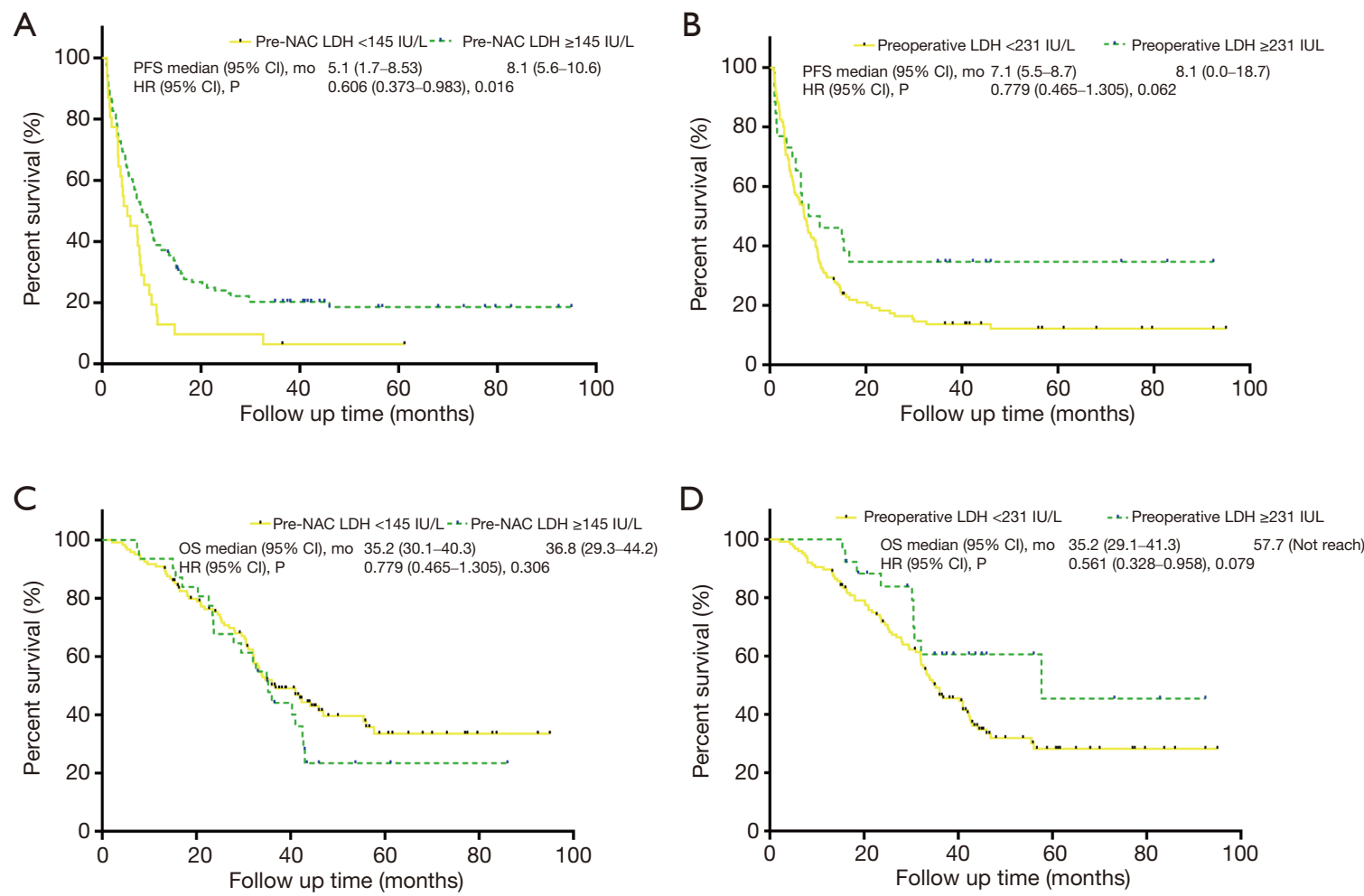

Figure 2 Survival analysis of different LDH levels. (A) PFS analysis of CRLM patients with LDH <145 IU/L versus CRLM patients with $\mathrm{LDH} \geq 145 \mathrm{IU} / \mathrm{L}$ ( $\mathrm{P}=0.016$, mPFS: 5.1 vs. 8.1 months, respectively). (B) Progression-free survival analysis of CRLM patients with $\mathrm{LDH}<231 \mathrm{IU} / \mathrm{L}$ versus CRLM patients with $\mathrm{LDH} \geq 231 \mathrm{IU} / \mathrm{L}$ ( $\mathrm{P}=0.062$, mPFS: 7.1 vs. 8.1 months, respectively). (C) OS analysis of CRLM patients with $\mathrm{LDH}<145 \mathrm{IU} / \mathrm{L}$ versus CRLM patients with $\mathrm{LDH} \geq 145 \mathrm{IU} / \mathrm{L}$ ( $\mathrm{P}=0.306$, mOS: 35.2 vs. 36.8 months, respectively). (D) Overall survival analysis of CRLM patients with $\mathrm{LDH}<231 \mathrm{IU} / \mathrm{L}$ versus CRLM patients with LDH $\geq 231 \mathrm{IU} / \mathrm{L}$ (P=0.079, mOS: 35.2 vs. 57.7 months, respectively). LDH, lactate dehydrogenase; CRLM, colorectal liver metastases; PFS, progression-free survival; OS, overall survival; IU, international unit.
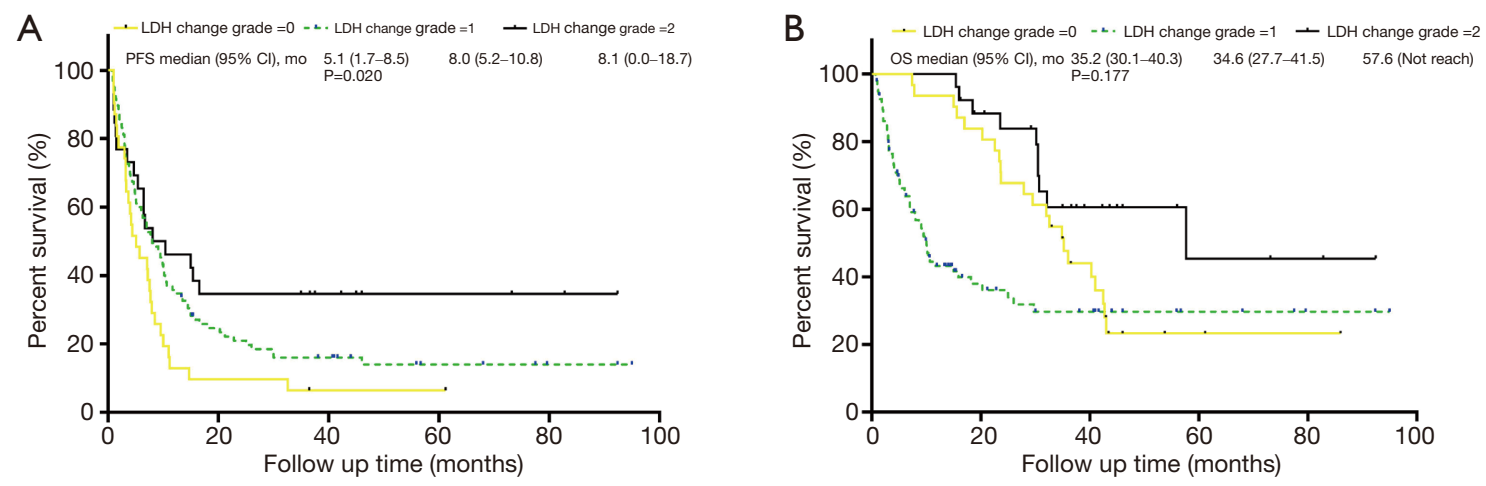

Figure 3 Survival analysis of LDH level change with three grades (0, 1, or 2). (A) PFS of CRLM patients with LDH change grade=0, LDH change grade $=1$ and $\mathrm{LDH}$ change grade $=2(\mathrm{P}=0.020$, mPFS: 5.1 vs. 8.0 vs. 8.1 months, respectively). (B) OS of CRLM patients with LDH change grade $=0, \mathrm{LDH}$ change grade $=1$ and $\mathrm{LDH}$ change grade $=2(\mathrm{P}=0.177$, mOS: 35.2 vs. 34.6 vs. 57.6 months, respectively). LDH, lactate dehydrogenase; CRLM, colorectal liver metastases; PFS, progression-free survival; OS, overall survival. 
Table 4 Prognostic factors for progression-free survival for colorectal liver metastases patients who underwent surgery after neo-adjuvant chemotherapy

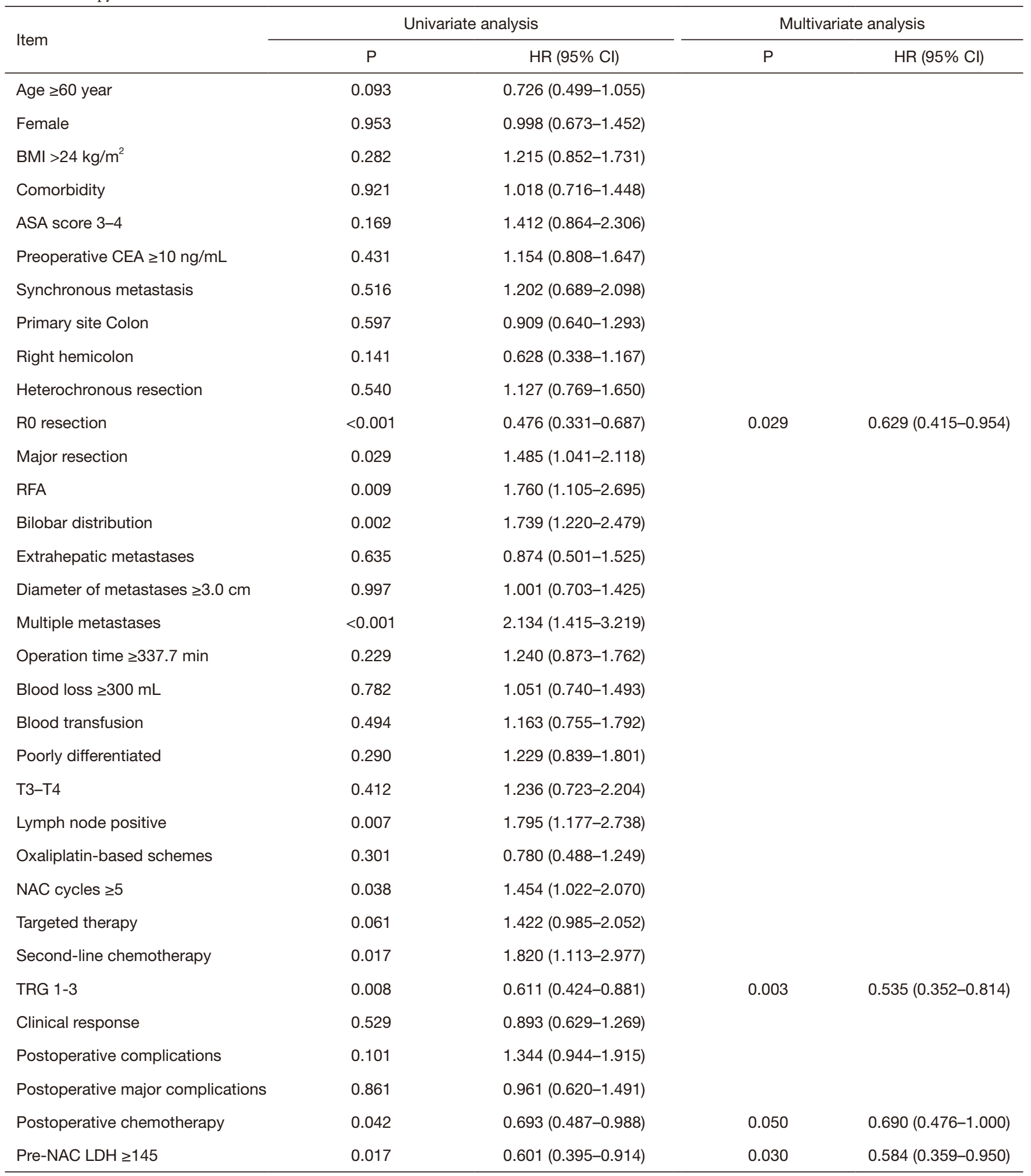

Table 4 (continued) 
Table 4 (continued)

\begin{tabular}{|c|c|c|c|c|}
\hline Item & \multicolumn{2}{|c|}{ Univariate analysis } & \multicolumn{2}{|c|}{ Multivariate analysis } \\
\hline Preoperative LDH $\geq 231$ & 0.065 & $0.617(0.369-1.031)$ & & \\
\hline LDH change grade $=0$ & - & Reference & - & Reference \\
\hline LDH change grade $=1$ & 0.048 & $0.649(0.423-0.997)$ & 0.030 & $0.584(0.359-0.950)$ \\
\hline
\end{tabular}

BMI, body mass index; ASA, American Society of Anesthesiologists; CEA, carcino-embryonic antigen; RFA, radiofrequency ablation; LDH, lactate dehydrogenase; NAC, neo-adjuvant chemotherapy; TRG, tumor regression grade.

several malignancies (23-28), including CRC $(25,28)$. Given the possible effects of chemotherapy on serum LDH levels, there is significantly more clinical utility in investigating the predictive ability of LDH levels before patients receive NAC. This may provide information about the effectiveness of NAC and the biological characteristics of tumors. In this study, we found that worse TRG was more common among patients with a grade $2 \mathrm{LDH}$ level change, which indicated that elevated LDH levels were a risk factor of poor pathological response. Pre-NAC LDH levels may be related to the nature of the tumor, as pre-NAC LDH levels was not affected by treatment (29).

The mechanism of LDH involvement in poor pathological response remains unclear; however, several possible mechanisms may be involved. First, LDH plays a crucial role in the Warburg effect, which is a common phenomenon in cancer cells. Unlike normal differentiated cells that generate energy by glycolysis only under anaerobic conditions, most cancer cells rely on aerobic glycolysis for energy generation (30). LDH is a key enzyme for glycolysis, which catalyzes the conversion of glucose to lactate. The Warburg effect seems to be a common feature of malignant cells that is important for their tumorigenic potential. Serum LDH levels reflect cellular metabolism and enzyme release by tumors $(30,31)$. Second, previous studies have shown that MYC and PI3K/Akt/mTOR pathways regulate cellular LDH expression levels at translational and transcriptional levels $(32,33)$. Thus, changes in LDH levels may present a reflection of aberrant oncogene activity. The pathological response of NAC in $50 \%$ of patients was poor, and chemotherapeutics may have side effects $(34,35)$. Thus, higher LDH levels may indicate that a chemotherapy scheme is not the most eligible scheme for patients or that the most optimal time to receive surgery is not after receiving NAC treatment. Pre-NAC LDH levels may be a potentially effective and easily available marker to select patients who would benefit from NAC. Patients with elevated pre-NAC LDH levels may represent a suitable population for whom a multimodality treatment approach would improve the pathological response of NAC.

Our study found that major postoperative complications were more likely to appear in patients with elevated preNAC LDH levels and elevated preoperative LDH levels. There are several possible reasons for this phenomenon. First, elevated LDH serum levels are thought to result from enzyme leakage following the destruction of hepatocytes, especially in patients with hepatitis (36). In addition, it has been proven that hepatocytes increase the production of LDH under hypoxic conditions until they become necrotic (37). Massive hepatocyte necrosis is the most notable character of acute liver failure resulting from liver resection.

Additionally, LDH can be an accurate symbol of hepatic injury $(38,39)$. Further, LDH levels are associated with the dysfunction of various organs $(40,41)$, which can lead to major postoperative complications. Previous studies have shown that the mortality and recurrence rates of patients with postoperative complications were $43 \%$ and $38 \%$ higher than those without complications, respectively (42). Our findings have led us to reach the same conclusion. Consequently, such an invasive procedure for patients with increased LDH levels may decrease the quality of life, extend recovery time, and increase economic and physical stress.

Recent studies have indicated that pre-treatment $\mathrm{LDH}$ levels significantly predict the outcome of metastatic CRC patients treated with chemotherapy (35). However, the predictive value of LDH in CRLM patients is unclear. This study found that increased LDH levels were significantly correlated with favorable PFS and OS in CRLM patients 
Table 5 Prognostic factors for overall survival for colorectal liver metastases patients who underwent surgery after neo-adjuvant chemotherapy

\begin{tabular}{|c|c|c|c|c|}
\hline Item & \multicolumn{2}{|c|}{ Univariate analysis } & \multicolumn{2}{|c|}{ Multivariate analysis } \\
\hline Age $\geq 60$ year & 0.214 & $0.753(0.481-1.178)$ & & \\
\hline Female & 0.789 & $0.941(0.601-1.472)$ & & \\
\hline $\mathrm{BMI}>24 \mathrm{~kg} / \mathrm{m}^{2}$ & 0.217 & 1.306 (0.855-1.995) & & \\
\hline ASA score 3-4 & 0.662 & $1.155(0.652-2.044)$ & & \\
\hline Preoperative CEA $\geq 10 \mathrm{ng} / \mathrm{mL}$ & 0.454 & $1.173(0.773-1.780)$ & & \\
\hline Synchronous metastasis & 0.926 & $1.032(0.533-1.998)$ & & \\
\hline Primary site Colon & 0.867 & $0965(0.636-1.464)$ & & \\
\hline $\mathrm{R} 0$ resection & $<0.001$ & $0.390(0.256-0.596)$ & $<0.001$ & $0.378(0.231-0.619)$ \\
\hline Major resection & 0.053 & $1.515(0.994-2.310)$ & & \\
\hline RFA & 0.080 & $1.541(0.950-2.499)$ & & \\
\hline Bilobar distribution & 0.012 & $1.712(1.125-2.605)$ & & \\
\hline Extrahepatic metastases & 0.939 & $0.974(0.504-1.882)$ & & \\
\hline Diameter of metastases $\geq 3.0 \mathrm{~cm}$ & 0.163 & $1.345(0.887-2.041)$ & & \\
\hline Multiple metastases & 0.028 & $1.719(1.060-2.786)$ & & \\
\hline Operation time $\geq 337.7 \mathrm{~min}$ & 0.763 & $1.066(0.703-1.617)$ & & \\
\hline Oxaliplatin-based schemes & 0.744 & $1.103(0.612-1.987)$ & & \\
\hline NAC cycles $\geq 5$ & 0.076 & $1.463(0.961-2.225)$ & & \\
\hline Targeted therapy & 0.262 & $1.282(0.831-1.977)$ & & \\
\hline Second-line chemotherapy & 0.008 & $2.137(1.220-3.745)$ & 0.001 & $3.091(1.578-6.054)$ \\
\hline TRG 1-3 & 0.030 & $0.618(0.400-0.955)$ & & \\
\hline Clinical response & 0.146 & $0.733(0.482-1.114)$ & & \\
\hline Postoperative complications & $<0.001$ & $2.369(1.536-3.653)$ & $<0.001$ & $2.566(1.596-4.216)$ \\
\hline Postoperative major complications & 0.615 & $1.150(0.668-1.981)$ & & \\
\hline Postoperative chemotherapy & 0.004 & $0.544(0.358-0.826)$ & 0.001 & $0.453(0.285-0.721)$ \\
\hline Pre-NAC LDH $\geq 145$ & 0.308 & $0.778(0.480-1.261)$ & & \\
\hline Preoperative LDH $\geq 231$ & 0.084 & $0.560(0.290-1.082)$ & 0.017 & $0.405(0.192-0.852)$ \\
\hline
\end{tabular}

Table 5 (continued) 
Table 5 (continued)

\begin{tabular}{|c|c|c|c|c|}
\hline Item & \multicolumn{2}{|c|}{ Univariate analysis } & \multicolumn{2}{|c|}{ Multivariate analysis } \\
\hline $\mathrm{LDH}$ change grade $=0$ & - & Reference & - & Reference \\
\hline $\mathrm{LDH}$ change grade $=1$ & 0.553 & $0.861(0.526-1.411)$ & 0.701 & $0.895(0.510-1.572)$ \\
\hline LDH change grade $=2$ & 0.071 & $0.502(0.237-1.061)$ & 0.017 & $0.362(0.157-0.834)$ \\
\hline
\end{tabular}

BMI, body mass index; ASA, American Society of Anesthesiologists; CEA, carcino-embryonic antigen; RFA, radiofrequency ablation; LDH, lactate dehydrogenase; NAC, neo-adjuvant chemotherapy; TRG, tumor regression grade.

receiving liver resection; however, these results differ from those of other studies (43). It may be that tumor cells obtain energy mainly through glycolysis, and LDH is the key catalytic enzyme for glycolysis. Tumor cells contain a considerable amount of LDH (13). After receiving NAC, tumor cells are destroyed by chemotherapy, leading to the release of LDH from destroyed cells. LDH level may indicate the extent of tumor destruction $(44,45)$. Thus, there appears to be a relationship between preoperative LDH levels and survival.

Considering that NAC may cause changes in LDH levels, as a combined predictor of the pre-NAC LDH levels and preoperative LDH levels, a grade of changes in $\mathrm{LDH}$ levels are comprehensive and accurate markers in CRLM patients. The grade is more capable to predict pathological response and postoperative complications and has some predictive effects on PFS and OS. Compared to tests for other potential predictive markers, the test used to measure serum LDH levels is inexpensive, widely used, and easy to perform. Thus, serum LDH levels can be used to guide the treatment of CRLM, and oncologists should consider monitoring dynamic changes in serum LDH levels.

This study had several limitations. First, this was a retrospective and single-center study, so selective bias was inevitable. Further, some toxicity events and complications may have been underreported, especially in less serious cases. In addition, the follow-up period for the survival analysis was relatively short, and the results of this study may require further validation from other cohorts of prospective studies. Despite these limitations, this study provides some guidance for clinical practice.

In conclusion, our study demonstrated that pre-NAC serum LDH levels, preoperative LDH levels, and changes in LDH levels have predictive effects on pathological response and prognosis in CRLM patients who undergo NAC followed by liver resection. Therefore, changes in serum LDH levels warrant more attention from oncologists, especially the dynamic monitoring of changes in $\mathrm{LDH}$ levels.

\section{Acknowledgments}

We would like to thank L. Huleatt and J. Chapnick for their help in polishing our paper.

Funding: This study was supported by the State Key Project on Infection Diseases of China [Grant number 2017ZX10201021-007-003], the National The capital health research and development of special [Grant number 20181-4021], the National Natural Science Foundation of China [Grant numbers 81672461, 81972311], CAMS Innovation Fund for Medical Sciences (CIFMS) [Grant number 201712M-4-002], the Non-profit Central Research Institution Fund of Chinese Academy of Medical Sciences [Grant number 2019PT310026] and Sanming Project of Medicine in Shenzhen [Grant number SZSM202011010].

\section{Footnote}

Reporting Checklist: The authors have completed the REMARK reporting checklist. Available at https://dx.doi. org/10.21037/apm-21-584

Data Sharing Statement: Available at https://dx.doi. org/10.21037/apm-21-584

Conflicts of Interest: All authors have completed the ICMJE uniform disclosure form (available at https://dx.doi. org/10.21037/apm-21-584). The authors have no conflicts of interest to declare.

Ethics Statement: The authors are accountable for all aspects of the work in ensuring that questions related 
to the accuracy or integrity of any part of the work are appropriately investigated and resolved. The study was conducted in accordance with the Declaration of Helsinki (as revised in 2013). The study was approved by the Institutional Review Board of the Ethics Committee of Cancer Hospital Chinese Academy of Medical Sciences (ID NCC2019C-016). All included patients gave their informed consent to participate in the study.

Open Access Statement: This is an Open Access article distributed in accordance with the Creative Commons Attribution-NonCommercial-NoDerivs 4.0 International License (CC BY-NC-ND 4.0), which permits the noncommercial replication and distribution of the article with the strict proviso that no changes or edits are made and the original work is properly cited (including links to both the formal publication through the relevant DOI and the license). See: https://creativecommons.org/licenses/by-nc-nd/4.0/.

\section{References}

1. Dekker E, Tanis PJ, Vleugels JLA, et al. Colorectal cancer. Lancet 2019;394:1467-80.

2. Hackl C, Neumann P, Gerken M, et al. Treatment of colorectal liver metastases in Germany: a ten-year population-based analysis of 5772 cases of primary colorectal adenocarcinoma. BMC Cancer 2014;14:810.

3. Engstrand J, Nilsson H, Strömberg C, et al. Colorectal cancer liver metastases - a population-based study on incidence, management and survival. BMC Cancer 2018;18:78.

4. Yoshino T, Arnold D, Taniguchi H, et al. Pan-Asian adapted ESMO consensus guidelines for the management of patients with metastatic colorectal cancer: a JSMOESMO initiative endorsed by CSCO, KACO, MOS, SSO and TOS. Ann Oncol 2018;29:44-70.

5. Mitry E, Fields AL, Bleiberg H, et al. Adjuvant chemotherapy after potentially curative resection of metastases from colorectal cancer: a pooled analysis of two randomized trials. J Clin Oncol 2008;26:4906-11.

6. Battula N, Tsapralis D, Mayer D, et al. Repeat liver resection for recurrent colorectal metastases: a singlecentre, 13-year experience. HPB (Oxford) 2014;16:157-63.

7. Kishi Y, Zorzi D, Contreras CM, et al. Extended preoperative chemotherapy does not improve pathologic response and increases postoperative liver insufficiency after hepatic resection for colorectal liver metastases. Ann Surg Oncol 2010;17:2870-6.
8. Du Pasquier C, Roulin D, Bize P, et al. Tumor response and outcome after reverse treatment for patients with synchronous colorectal liver metastasis: a cohort study. BMC Surg 2020;20:78.

9. Serayssol C, Maulat C, Breibach F, et al. Predictive factors of histological response of colorectal liver metastases after neoadjuvant chemotherapy. World J Gastrointest Oncol 2019;11:295-309.

10. Kim HS, Lee JM, Kim HS, et al. Prognosis of Synchronous Colorectal Liver Metastases After Simultaneous Curative-Intent Surgery According to Primary Tumor Location and KRAS Mutational Status. Ann Surg Oncol 2020;27:5150-8.

11. Chen Q, Zhao H, Wu J, et al. Preoperative D-dimer and Gamma-Glutamyltranspeptidase Predict Major Complications and Survival in Colorectal Liver Metastases Patients After Resection. Transl Oncol 2019;12:996-1004.

12. Frühling P, Hellberg K, Ejder P, et al. The prognostic value of $\mathrm{C}$-reactive protein and albumin in patients undergoing resection of colorectal liver metastases. A retrospective cohort study. HPB (Oxford) 2021;23:970-8.

13. Feron O. Pyruvate into lactate and back: from the Warburg effect to symbiotic energy fuel exchange in cancer cells. Radiother Oncol 2009;92:329-33.

14. Maftouh M, Avan A, Sciarrillo R, et al. Synergistic interaction of novel lactate dehydrogenase inhibitors with gemcitabine against pancreatic cancer cells in hypoxia. Br J Cancer 2014;110:172-82.

15. Greten FR, Grivennikov SI. Inflammation and Cancer: Triggers, Mechanisms, and Consequences. Immunity 2019;51:27-41.

16. Liu L, He Y, Ge G, et al. Lactate dehydrogenase and creatine kinase as poor prognostic factors in lung cancer: A retrospective observational study. PLoS One 2017;12:e0182168.

17. Li G, Wang Z, Xu J, et al. The prognostic value of lactate dehydrogenase levels in colorectal cancer: a meta-analysis. BMC Cancer 2016;16:249.

18. Namikawa T, Ishida N, Tsuda S, et al. Prognostic significance of serum alkaline phosphatase and lactate dehydrogenase levels in patients with unresectable advanced gastric cancer. Gastric Cancer 2019;22:684-91.

19. Liu D, Wang D, Wu C, et al. Prognostic significance of serum lactate dehydrogenase in patients with breast cancer: a meta-analysis. Cancer Manag Res 2019;11:3611-9.

20. Eisenhauer EA, Therasse P, Bogaerts J, et al. New response evaluation criteria in solid tumours: revised RECIST 
guideline (version 1.1). Eur J Cancer 2009;45:228-47.

21. Rubbia-Brandt L, Giostra E, Brezault C, et al. Importance of histological tumor response assessment in predicting the outcome in patients with colorectal liver metastases treated with neo-adjuvant chemotherapy followed by liver surgery. Ann Oncol 2007;18:299-304.

22. Dindo D, Demartines N, Clavien PA. Classification of surgical complications: a new proposal with evaluation in a cohort of 6336 patients and results of a survey. Ann Surg 2004;240:205-13

23. Ostergaard L, Tietze A, Nielsen T, et al. The relationship between tumor blood flow, angiogenesis, tumor hypoxia, and aerobic glycolysis. Cancer Res 2013;73:5618-24.

24. Brown JE, Cook RJ, Lipton A, et al. Serum lactate dehydrogenase is prognostic for survival in patients with bone metastases from breast cancer: a retrospective analysis in bisphosphonate-treated patients. Clin Cancer Res 2012;18:6348-55.

25. Bar J, Spencer S, Morgan S, et al. Correlation of lactate dehydrogenase isoenzyme profile with outcome in patients with advanced colorectal cancer treated with chemotherapy and bevacizumab or cediranib: Retrospective analysis of the HORIZON I study. Clin Colorectal Cancer 2014;13:46-53.

26. Faloppi L, Scartozzi M, Bianconi M, et al. The role of $\mathrm{LDH}$ serum levels in predicting global outcome in HCC patients treated with sorafenib: implications for clinical management. BMC Cancer 2014;14:110.

27. Armstrong AJ, George DJ, Halabi S. Serum lactate dehydrogenase predicts for overall survival benefit in patients with metastatic renal cell carcinoma treated with inhibition of mammalian target of rapamycin. J Clin Oncol 2012;30:3402-7.

28. Passardi A, Scarpi E, Tamberi S, et al. Impact of PreTreatment Lactate Dehydrogenase Levels on Prognosis and Bevacizumab Efficacy in Patients with Metastatic Colorectal Cancer. PLoS One 2015;10:e0134732.

29. Buder-Bakhaya K, Hassel JC. Biomarkers for Clinical Benefit of Immune Checkpoint Inhibitor Treatment-A Review From the Melanoma Perspective and Beyond. Front Immunol 2018;9:1474.

30. Vander Heiden MG, Cantley LC, Thompson CB. Understanding the Warburg effect: the metabolic requirements of cell proliferation. Science 2009;324:1029-33.

31. Sun Q, Chen X, Ma J, et al. Mammalian target of rapamycin up-regulation of pyruvate kinase isoenzyme type M2 is critical for aerobic glycolysis and tumor growth.
Proc Natl Acad Sci U S A 2011;108:4129-34.

32. Kim JW, Dang CV. Cancer's molecular sweet tooth and the Warburg effect. Cancer Res 2006;66:8927-30.

33. Kim JW, Dang CV. Multifaceted roles of glycolytic enzymes. Trends Biochem Sci 2005;30:142-50.

34. Nordlinger B, Sorbye H, Glimelius B, et al. Perioperative chemotherapy with FOLFOX4 and surgery versus surgery alone for resectable liver metastases from colorectal cancer (EORTC Intergroup trial 40983): a randomised controlled trial. Lancet 2008;371:1007-16.

35. Tamandl D, Klinger M, Eipeldauer S, et al. Sinusoidal obstruction syndrome impairs long-term outcome of colorectal liver metastases treated with resection after neoadjuvant chemotherapy. Ann Surg Oncol 2011;18:421-30.

36. Kotoh K, Enjoji M, Kato M, et al. A new parameter using serum lactate dehydrogenase and alanine aminotransferase level is useful for predicting the prognosis of patients at an early stage of acute liver injury: a retrospective study. Comp Hepatol 2008;7:6.

37. Kotoh K, Kato M, Kohjima M, et al. Lactate dehydrogenase production in hepatocytes is increased at an early stage of acute liver failure. Exp Ther Med 2011;2:195-9.

38. Wang Y, Liu H, Liu S, et al. Incidence, predictors and prognosis of genotype 4 hepatitis E related liver failure: A tertiary nested case-control study. Liver Int 2019;39:2291-300.

39. Ferriero R, Nusco E, De Cegli R, et al. Pyruvate dehydrogenase complex and lactate dehydrogenase are targets for therapy of acute liver failure. J Hepatol 2018;69:325-35.

40. Gong H, Sheng X, Xue J, et al. Expression and role of TNIP2 in multiple organ dysfunction syndrome following severe trauma. Mol Med Rep 2019;19:2906-12.

41. Su Y, Ju MJ, Ma JF, et al. Lactate dehydrogenase as a prognostic marker of renal transplant recipients with severe community-acquired pneumonia: a 10-year retrospective study. Ann Transl Med 2019;7:660.

42. Dorcaratto D, Mazzinari G, Fernandez M, et al. Impact of Postoperative Complications on Survival and Recurrence After Resection of Colorectal Liver Metastases: Systematic Review and Meta-analysis. Ann Surg 2019;270:1018-27.

43. Miao P, Sheng S, Sun X, et al. Lactate dehydrogenase A in cancer: a promising target for diagnosis and therapy. IUBMB Life 2013;65:904-10.

44. Urbańska K, Orzechowski A. Unappreciated Role of 
LDHA and LDHB to Control Apoptosis and Autophagy in Tumor Cells. Int J Mol Sci 2019;20:2085.

45. Pathria G, Scott DA, Feng Y, et al. Targeting the
Warburg effect via LDHA inhibition engages

ATF4 signaling for cancer cell survival. EMBO J 2018;37:e99735.

Cite this article as: Chen J, Chen Q, Yao J, Jiang Y, Zhou J, Zhao H, Cai J. Changes in serum lactate dehydrogenase levels as markers of pathological response and prognosis in colorectal liver metastases patients receiving neoadjuvant chemotherapy followed by resection. Ann Palliat Med 2021;10(10):10276-10292 . doi: 10.21037/apm-21-584 